\title{
Analysis of Patients Undergoing Colonoscopies and the Importance of Exam Quality for Colorectal Cancer Screening
}

\author{
Marcos Venícios Furlanetto ${ }^{10}$ Jaqueline Alves Zwierzikowski ${ }^{20}$ Carolina Fischer Bertoldo ${ }^{20}$ \\ Guilherme Andretta Sotto Maior Wistuba ${ }^{20}$ Eduardo Issao Brand Tashima1() \\ Ana Helena Bessa Gonçalves Vieira ${ }^{10}$ Henrique Luckow Invitti ${ }^{1}$ Antonio Sérgio Brenner ${ }^{1}$ \\ ${ }^{1}$ Colorectal Surgery Department, Hospital Universitário Evangélico \\ Mackenzie, Curitiba, PR, Brazil \\ 2 Universidade Federal do Paraná (UFPR), Curitiba, PR, Brazil \\ Address for correspondence Marcos Venícios Furlanetto, Colorectal \\ Surgery Resident Physician, Rua Visconde de Taunay, 824, Joinville- Santa \\ Catarina 89203-005, Brazil (e-mail: marcosv.furlanetto@gmail.com).
}

J Coloproctol 2022;42(1):14-19.

\author{
Summary \\ Keywords \\ - adenoma \\ - colorectal neoplasms \\ - colonoscopy \\ - colonic polyps
}

Objective To determine the impact of the quality of colonoscopy examination for colorectal cancer screening.

Methods Retrospective observational study of medical records from patients treated at the endoscopy and colonoscopy service of Hospital Universitário Evangélico Mackenzie (Curitiba, PR, Brazil) from January 2019 to January 2020.

Results The analysis was based on 337 medical records from patients with adenomas identified during colonoscopy, and 1,385 medical records from patients without adenomas. The estimated occurrence rate of diagnosis of adenoma during colonoscopy in the target population of the study was of $19.6 \%$, with a $95 \%$ confidence interval ranging from 17.7 to $21.5 \%$. Of the 337 patients with adenoma, $136(40.4 \%)$ presented the advanced form. Statistical analysis indicated a significant association between the quality of colonoscopy preparation and test completion.

Conclusion The quality of colonoscopy images is a critical factor for colorectal cancer screening, as it leads to higher rates of adenoma detection and test completion.

\section{Introduction}

Colorectal cancer (CRC) is the fourth most common type of cancer among adults in the United States. It is the second leading cause of death by cancer in that country, with more than 50,000 deaths each year. ${ }^{1}$

In Brazil, there is an estimate of 20,540 and 20,470 cases of CRC in men and women, respectively, occurring each year of the 2020 to 2022 triennium. These figures correspond to an estimated risk of 19.64 new cases per 100,000 men and 19.03 per 100,000 women. Excluding non-melanoma skin tumors, CRC is the second most frequent neoplasm in men from the Southeast $(28.62 / 100,000)$ and Midwest $(15.40 / 100,000)$ Brazilian regions. It is the third most frequent tumor in Southern Brazil $(25.11 / 100,000)$, according to the 2020 estimate of the Brazilian National Cancer Institute (INCA). Adenoma screening and removal is associated with a lower incidence of cancer. The early detection of adenoma also helps guide counseling regarding periodic surveillance using colonoscopy. ${ }^{2-4}$ received

April 12, 2021

accepted after revision

October 25, 2021

published online

January 31,2022
DOI https://doi.org/

$10.1055 / \mathrm{s}-0042-1742309$.

ISSN 2237-9363.

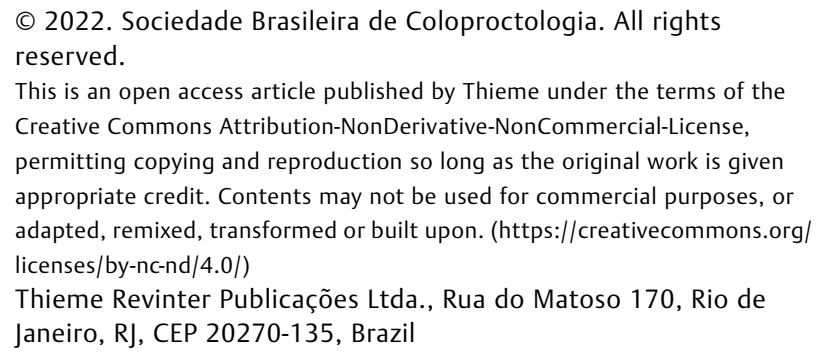

This is an open access article published by Thieme under the terms of the Creative Commons Attribution-NonDerivative-NonCommercial-License, permitting copying and reproduction so long as the original work is given appropriate credit. Contents may not be used for commercial purposes, or adapted, remixed, transformed or built upon. (https://creativecommons.org/ licenses/by-nc-nd/4.0/)

Thieme Revinter Publicações Ltda., Rua do Matoso 170, Rio de Janeiro, RJ, CEP 20270-135, Brazil 
The most important factor in detecting polyps is the examiner's performance, regardless of patient-related factors. The increased number of detected lesions also relies on high-quality colonoscopies, better equipment, and good colon preparation. $2,5,6$

Advanced adenomas are defined as adenomas with more than three lesions, at least one adenoma larger than $10 \mathrm{~mm}$, at least one adenoma with high-grade dysplasia, villous adenoma, or a combination of these characteristics. Advanced adenomas are very relevant due to their association with a higher risk of CRC and development of metachronous lesions. Therefore, post-polypectomy surveillance recommendations warrant a higher frequency of reassessment. ${ }^{2-4,6-9}$

Detection rate improvement requires the following test quality criteria: A) proper colonoscopy time, ensuring a minimum of 30 minutes for each primary diagnostic and screening colonoscopy, and a minimum of 45 minutes for each colonoscopy due to a positive fecal occult blood test. B) Referral evaluation. C) Bowel preparation, which is considered adequate if it allows the detection of polyps $>5 \mathrm{~mm}$ in size and presents a $\geq 6$ score on the Boston scale (with a minimum of 2 points for each segment), or a $\leq 7$ score on the Ottawa scale; in addition, at least $\geq 90 \%$ of procedures should be properly followed, with a goal of $\geq 95 \%$. D) Cecal intubation rates, with the minimum being above $90 \%$, and a goal of $95 \%$; E) Device withdrawal time of at least 6 minutes. F) Adenoma detection rate (ADR) according to the European Society of Gastrointestinal Endoscopy (ESGE) and the American Society for Gastrointestinal Endoscopy (ASGE) guidelines, which recommend an ADR of $\geq 25 \%$; the ASGE also suggests a gender-based threshold for ADR of $\geq 30 \%$ for men and $\geq 20 \%$ for women.; G) Appropriate lesion management (polypectomy technique, polyp recovery, resection site, and tattooing); and $\mathrm{H}$ ) adequate follow-up intervals. The most important of all recommended measures is ADR. ${ }^{10}$

Adenoma detection rate is the proportion of screening colonoscopies with at least one adenoma found. An ADR lower than $20 \%$ is associated with a $10 \%$ higher risk of interval cancer when compared to detection rates greater than $20 \%$. Therefore, higher ADRs are directly proportional to better clinical outcomes. ${ }^{5,10-13}$

Known risk factors for CRC include age over 50 years, male gender, smoking, obesity, diabetes, as well as family history, and genetic predisposition to cancer. ${ }^{14,15}$

Most studies recommend starting colonoscopy screening at 50 years old for the medium-risk population. Since it is not uncommon in daily clinical practice to find advanced adenomas or neoplasms in younger people, some guidelines have recommended starting screening at 45 years old, including the updated CRC screening guidelines from the American Cancer Society (ACS). 1,16

Our main objective was to determine the impact of the quality of the colonoscopy examination for CRC screening. A secondary goal was to describe ADR in our service.

\section{Methods}

\section{Study type}

A retrospective observational study was conducted to analyze the medical records of patients treated at the endoscopy and colonoscopy service of Hospital Universitário Evangélico Mackenzie (HUEM) in Curitiba, PR, Brazil, from January 2019 to January 2020. The Research Ethics Committee from HUEM approved this research project under the Certificate of Ethical Appreciation Presentation number 36201420.7.0000.0103, opinion number 4.221.329.

\section{Inclusion criteria}

A total of 1,722 medical records from patients aged 18 years old and older who underwent colonoscopy from January 2019 to January 2020 were included and evaluated.

\section{Exclusion criteria}

Patients under 18 years old, and those whose medical records had insufficient data for analysis were excluded from this study.

\section{Analyzed variables}

The patient-related variables collected and analyzed here included gender, age, smoking, comorbidities, as well as personal and family history of CRC. The procedure-related variables were complete colonoscopies, cecal intubation, and colon preparation conditions. We also analyzed the variables related to adenomatous polyp, such as location, size, morphology, and histological patterns. Advanced adenomatous polyps were differentiated.

At our hospital, the method of colon preparation classification is based partially on the Ottawa Scale, according to the following criteria: Good - clearly visible mucosal detail with almost no stool residues, or some cloudy liquid or stool residues with mucosal details still visible with no need for lavage/suction. Regular - some cloudy fluid from stool residues obscuring mucosal details, which become visible with suction, but no lavage required. Poor - stools obscure mucosal details and contours, and visualization is moderate after suction and lavage. Inadequate - solid stools obscure mucosal details, and lavage and suction do not remove them. ${ }^{17}$

As this was a retrospective study, not all medical records had information on certain variables. Thus, sample numbers (n) for each variable represent the number of medical records or polyps with relevant data.

\section{Statistical validation}

Quantitative variables were described as mean, standard deviation (SD), and minimum and maximum values. Categorical variables were described as frequency and percentage values. Adenoma occurrence rates estimates were based on 95\% confidence intervals $(95 \% \mathrm{CI})$. The association between two categorical variables was analyzed using the chi-squared test. Values of $p<0.05$ indicated statistical significance. Data were analyzed using the Statistical Package for the Social Sciences, Standard Edition (StataCorp LLC. College Station, TX, USA) software, version 14.1. 
Table 1 Patient-related variables

\begin{tabular}{|c|c|c|c|}
\hline Variable & Valid $n$ & Classification & Result* \\
\hline Age (years old) & 337 & & $\begin{array}{l}64.2 \pm 10.0 \\
(25-88)\end{array}$ \\
\hline \multirow{2}{*}{$\begin{array}{l}\text { Age range } \\
\text { (years old) }\end{array}$} & 337 & $18-50$ & $24(7.1 \%)$ \\
\hline & & Over 50 & $313(92.9 \%)$ \\
\hline \multirow[t]{2}{*}{ Gender } & 337 & Female & 196 (58.2\%) \\
\hline & & Male & $141(41.8 \%)$ \\
\hline \multirow[t]{3}{*}{ Smoking } & 306 & Yes & $45(14.7 \%)$ \\
\hline & & No & $212(69.3 \%)$ \\
\hline & & Ex & $49(16.0 \%)$ \\
\hline \multirow{2}{*}{$\begin{array}{l}\text { Systemic arterial } \\
\text { hypertension }\end{array}$} & 306 & No & $170(55.6 \%)$ \\
\hline & & Yes & $136(44.4 \%)$ \\
\hline \multirow{2}{*}{$\begin{array}{l}\text { Diabetes } \\
\text { mellitus II }\end{array}$} & 304 & No & $251(82.6 \%)$ \\
\hline & & Yes & $53(17.4 \%)$ \\
\hline \multirow[t]{2}{*}{ Coronary disease } & 308 & No & $271(88.0 \%)$ \\
\hline & & Yes & 37 (12.0\%) \\
\hline \multirow{2}{*}{$\begin{array}{l}\text { Colorectal } \\
\text { neoplasm }\end{array}$} & 308 & No & $284(92.2 \%)$ \\
\hline & & Yes & $24(7.8 \%)$ \\
\hline \multirow[t]{2}{*}{ Family history** } & 307 & No & $260(84.7 \%)$ \\
\hline & & Yes & $47(15.3 \%)$ \\
\hline \multirow{4}{*}{$\begin{array}{l}\text { Colonoscopy } \\
\text { preparation }\end{array}$} & 337 & Good & $162(48.1 \%)$ \\
\hline & & Regular & $126(37.4 \%)$ \\
\hline & & Bad & $23(6.8 \%)$ \\
\hline & & Inadequate & $26(7.7 \%)$ \\
\hline \multirow[t]{2}{*}{ Test completion } & 336 & Yes & $311(92.6 \%)$ \\
\hline & & No & $25(7.4 \%)$ \\
\hline \multirow[t]{2}{*}{ If not, why? } & 22 & $\begin{array}{l}\text { Technical } \\
\text { difficulty }\end{array}$ & $10(43.5 \%)$ \\
\hline & & $\begin{array}{l}\text { Improper } \\
\text { preparation }\end{array}$ & $12(52.2 \%)$ \\
\hline \multirow{5}{*}{$\begin{array}{l}\text { Number of } \\
\text { adenomas }\end{array}$} & 337 & 1 & $188(55.8 \%)$ \\
\hline & & 2 & $73(21.7 \%)$ \\
\hline & & 3 & $33(9.8 \%)$ \\
\hline & & 4 & $21(6.2 \%)$ \\
\hline & & 5 or more & $22(6.5 \%)$ \\
\hline \multirow{2}{*}{$\begin{array}{l}\text { Advanced } \\
\text { adenoma*** }\end{array}$} & 337 & No & 201 (59.6\%) \\
\hline & & Yes & $136(40.4 \%)$ \\
\hline
\end{tabular}

Notes: *Described as "mean \pm standard deviation (minimum-maximum)" or "frequency (percentage)". *A positive family history for colorectal cancer is defined as the presence of a first-degree relative with colorectal cancer before the age of 50 years old or a known history of a genetic syndrome linked to colorectal cancer. ${ }^{* * *}$ Defined by the presence of more than three lesions, at least one adenoma larger than $10 \mathrm{~mm}$, at least one adenoma with high-grade dysplasia, villous adenoma, or combinations of these characteristics.

\section{Results}

Our analysis was based on 337 medical records from patients with adenomas discovered during colonoscopy, and a control group composed of 1,385 medical records from patients without adenomas. - Table 1 shows that most patients were females (58.2\%), with a mean age of 64.2 years (25-88 years).

Patients with or without adenomas presented significant differences. For the adenoma group, mean age was 5.5 years higher, and there were $7.1 \%$ more male patients, when compared with the control group (-Table 2 ).

The estimated occurrence rate of adenoma detection during colonoscopy in the target population was of $19.6 \%$, with a $95 \% \mathrm{CI}$ ranging from 17.7 to $21.5 \%$.

Of the 337 patients with adenoma, 136 (40.4\%) had advanced adenoma, with a $95 \% \mathrm{CI}$ ranging from 35.1 to $45.6 \%$.

- Table 3 presents adenomatous polyps-related factors. Data from up to five polyps were recorded for each patient. Not all polyps detected had all their analyzed characteristics included in the medical record. Thus, $n$ reflects the number of polyps with analyzed features.

Dysplasia was classified as low-grade or high-grade. Adenomas with low-grade dysplasia presented mild or moderate dysplastic changes. Both the adenomas with severe dysplasia and those with carcinoma in situ were deemed lesions with high-grade dysplasia. ${ }^{18}$

We tested a null hypothesis of the lack of association between polyp size ( $\leq 10 \mathrm{~mm}$ or $>10 \mathrm{~mm}$ ), and dysplasia classification against the alternative hypothesis of an actual association (-Table 4 ).

Data on size and dysplasia were available for 481 polyps: 448 with size $\leq 10 \mathrm{~mm}$ and 33 with size $>10 \mathrm{~mm}$. Since the remaining polyps had no available data for one or both variables, analysis encompassed all polyps with valid data.

Statistical tests indicated the existence of a significant association between polyp size and dysplasia. - Table $\mathbf{4}$ shows that polyps bigger than $10 \mathrm{~mm}$ present a higher percentage of high-grade dysplasia and a lower rate of absent dysplasia.

We also tested the null hypothesis of no association between the quality of colon preparation and test completion versus the alternative hypothesis of an actual association (-Table 5).

The statistical test indicated a significant association between the quality of colonoscopy preparation and colonoscopy completion. The data in - Table $\mathbf{5}$ show that poor or inadequate preparation resulted in a higher number of incomplete tests compared to good or regular preparation.

\section{Discussion}

According to the literature, $\mathrm{CRC}$ is associated with older age. Although ACS recommends CRC screening in average-risk subjects starting at 45 years old, other programs recommend screening in people aged 50 and older. ${ }^{1,15,19,20}$ Among the adenoma-related aspects evaluated here, age above 50 years old was an independent risk factor since its association with the disease was significantly different between the two groups. 
Table 2 Age and gender variables in patients with or without adenoma

\begin{tabular}{|l|l|l|l|l|}
\hline Variable & Classification & Group & P-value \\
\cline { 3 - 5 } & & Without adenoma* & With adenoma* & \\
\hline Age (years old) & & $58.7 \pm 14.1(11-94)$ & $64.2 \pm 10.0(25-88)$ & $<0.001$ \\
\hline Age range & 18 to 50 & $315(23.5 \%)$ & $24(7.1 \%)$ & \\
\hline & Over 50 & $1,028(76.5 \%)$ & $313(92.9 \%)$ & $<0.001$ \\
\hline Gender & Female & $906(65.4 \%)$ & $196(58.3 \%)$ & \\
\hline & Male & $479(34.6 \%)$ & $140(41.7 \%)$ & 0.015 \\
\hline
\end{tabular}

Note: *Described as “mean \pm standard deviation (minimum - maximum)" or "frequency (percentage)."

Table 3 Adenomatous polyp-related variables

\begin{tabular}{|l|l|l|l|}
\hline Variable & $\begin{array}{l}\text { Valid } \\
\mathbf{n}\end{array}$ & Classification & Result* \\
\hline Size (mm) & 615 & & $\begin{array}{l}5.3 \pm 4.9 \\
(1-40)\end{array}$ \\
\hline Location & 632 & Cecum & $49(7.8 \%)$ \\
\hline & & Ascending colon & $82(13 \%)$ \\
\hline & & Transverse colon & $84(13.3 \%)$ \\
\hline & & Descending colon & $73(11.6 \%)$ \\
\hline & & Sigmoid colon & $160(25.3 \%)$ \\
\hline Morphology & 625 & Pectum & $184(29 \%)$ \\
\hline & & Sessile & $78(12.5 \%)$ \\
\hline $\begin{array}{l}\text { Adenoma } \\
\text { histological } \\
\text { type }\end{array}$ & 521 & Tubular & $547(87.5 \%)$ \\
\hline & & Serrated & $423(81.2 \%)$ \\
\hline & Tubulovillous & $37(7.1 \%)$ \\
\hline $\begin{array}{l}\text { Dysplasia } \\
\text { classification }\end{array}$ & 516 & Villous & $1(0.2 \%)$ \\
\hline & How grade & $383(74 \%)$ \\
\hline
\end{tabular}

Note: *Described as "mean \pm standard deviation (minimum-maximum)" or "frequency (percentage)."

Table 4 Relationship between polyp size and grade of dysplasia

\begin{tabular}{|l|l|l|}
\hline \multirow{2}{*}{ Dysplasia } & \multicolumn{2}{|l|}{ Size $(\mathrm{mm})$} \\
\cline { 2 - 3 } & $\leq \mathbf{1 0}$ & $>10$ \\
\hline Low grade & 344 & 12 \\
\hline & $76.8 \%$ & $36.4 \%$ \\
\hline High grade & 104 & 21 \\
\hline & $23.2 \%$ & $63.6 \%$ \\
\hline Total & 448 & 33 \\
\hline
\end{tabular}

Note: $P$-value $<0.001 ;$ Chi-squared test $p<0.05$.
Table 5 Relationship between colonoscopy preparation and test completion

\begin{tabular}{|l|l|l|l|l|}
\hline \multirow{2}{*}{$\begin{array}{l}\text { Complete } \\
\text { test }\end{array}$} & \multicolumn{4}{|l|}{ Colonoscopy preparation } \\
\cline { 2 - 5 } & Good & Regular & Bad & Inadequate \\
\hline Yes & 152 & 121 & 18 & 20 \\
\hline & $94.4 \%$ & $96.0 \%$ & $78.3 \%$ & $76.9 \%$ \\
\hline No & 9 & 5 & 5 & 6 \\
\hline & $5.6 \%$ & $4.0 \%$ & $21.7 \%$ & $23.1 \%$ \\
\hline Total & 161 & 126 & 23 & 26 \\
\hline
\end{tabular}

Note: $P$-value $<0.001$; Chi-squared test $p<0.05$.

Several clinical and lifestyle-related risk factors for CRC were described in the literature, including smoking, alcohol intake, high blood pressure, dyslipidemia, diabetes, and obesity. ${ }^{15} \mathrm{~A}$ comparative analysis of some of these factors in patients with adenomas allowed the description of characteristics of this study's population. According to data from the Brazilian Health Department (VIGITEL, 2019), the frequency of diabetes and arterial hypertension is of approximately $7.7 \%$ and $24.7 \%$, respectively, in Brazilian subjects of both genders; in addition, the percentage of adult smokers in Curitiba is of $11.4 \%$ for both genders. This demonstrates a disparity between arterial hypertension and adenomas in our sample (44.4\%) since the remaining risk factors were closer to its occurrence in the general population. $^{21}$

Among the 1,722 colonoscopies evaluated at our institution, ADR was deemed adequate and within the confidence interval, albeit borderline, leading us to consider potential improvements. ${ }^{5,11-13}$ We know that high ADRs achieved by endoscopists result in lower rates of interval CRC, as well as lower rates of advancedCRC. ${ }^{11,13}$ It is important to highlight that our ADR has limitations, as tests were performed by different examiners at a medical residency service which trains new endoscopists. As such, we must consider that endoscopists with similar individual ADRs may impact the total adenoma detection rate, as there are differences between ADR and the number of adenomas per colonoscopy (APC). While ADR has the best-established goal, it is a "one and done" parameter, as the endoscopist may reach the target ADR and perform a poor-quality test, leading to a 
wide range of total rates. Minimum APC targets were proposed but not endorsed by any consensus. ${ }^{9,12}$

Several techniques may improve colonoscopy and increase ADR, including better colon preparation, device withdrawal time greater than 6 minutes, and dynamic changes in positioning. Even so, many lesions go unnoticed. In an attempt to minimize these mistakes, mechanical and optical devices were developed for methodological improvement, leading to better outcomes. ${ }^{13}$ In our opinion, these devices should be widely available, economically viable, simple to use, reliable, and highly effective. However, our institution is philanthropical and a regional reference center within the Brazilian Unified Health System, so access to such equipment is challenging, and its impact on clinical practice is debatable.

A proper bowel preparation is essential for optimal visualization of the intestinal mucosa, minimizing the risk of non-detection of lesions. ${ }^{17}$ In addition, inadequate bowel preparation is related to lower rates of lesion detection, less satisfactory overall outcomes, increased frequency of postcolonoscopy surveillance, lower rates of cecal intubation, and lengthy procedures that may result in increased costs. ${ }^{17}$ Our study showed a significant association between the quality of bowel preparation and test completion. Even though performing high-quality procedures within a public health service can be challenging, it is important to look for methods to improve outcomes. A viable and easy-to-apply option in clinical practice is the use of proprietary instruments, such as well-established and validated scales, to evaluate the quality of bowel preparation. ${ }^{17}$ The Boston scale is a validated, reliable, and easily reproducible instrument for assessing bowel preparation. ${ }^{22}$ Other aspects that impact the quality of colonoscopy exam include application mode, bowel preparation ingredients, and educational techniques. Educating patients is essential, but excessively technical information can make understanding difficult, especially for subjects with lower educational levels. ${ }^{22}$ Therefore, booklets with simple information about bowel preparation guidelines are valuable and can improve test quality.

It is well established in the literature that advanced polyps change the prognosis and increase the chance of CRC development. ${ }^{23}$ Although small polyps are the most frequent, in these cases lesions with advanced histological features are uncommon. ${ }^{24}$ Despite advances in technology and the high quality of endoscopic studies, we must emphasize that failure to recognize an adenoma in small polyps and, consequently, the use of the resect and discard strategy could lead to an erroneous low-risk classification and inappropriate patient follow-up. ${ }^{25}$ It is important to note that small polyps present a non-negligible risk of histological progression. Our research demonstrated that the polyp's size influences the chance of histological progression, although we could not attribute a clinical meaning to this finding.

\section{Conclusion}

The quality of colonoscopy examination is a critical factor for CRC screening, as it leads to higher rates of adenoma detection and test completion.

\section{Authors contributions}

Marcos Venícios Furlanetto: Project design, literature review, data organization, article writing and submission. Jaqueline Alves Zwierzikowski: Project design, literature review, data collection and organization, article writing and submission.

Carolina Fischer Bertoldo: Project design, literature review, data collection and organization, article writing and submission.

Guilherme Andretta Sotto Maior Wistuba: Project design, literature review, data collection and organization, article writing and submission.

Eduardo Issao Brand Tashima: Project design, literature review, data organization, article writing and submission. Ana Helena Bessa Gonçalves Vieira: Project supervision, roles delegation and supervision, review of the article writing and submission process.

Henrique Luckow Invitti: Project guidance, roles delegation and supervision, review of the article writing and submission process.

Antonio Sérgio Brenner: Project guidance, roles delegation and supervision, review of the article writing and submission process.

\section{Funding}

This work did not receive any kind of funding. All expenses were paid for by the researchers themselves.

\section{Conflict of Interests}

The authors have no conflict of interests to declare.

\section{References}

1 Wolf AMD, Fontham ETH, Church TR, et al. Colorectal cancer screening for average-risk adults: 2018 guideline update from the American Cancer Society. CA Cancer J Clin 2018;68(04):250-281. Doi: $10.3322 /$ caac. 21457

2 Dubé C, Yakubu M, McCurdy BR, et al. Risk of Advanced Adenoma, Colorectal Cancer, and Colorectal Cancer Mortality in People With Low-Risk Adenomas at Baseline Colonoscopy: A Systematic Review and Meta-Analysis. Am J Gastroenterol 2017;112(12): 1790-1801. Doi: 10.1038/ajg.2017.360

3 Outcomes M, Registration T. Association of Colonoscopy Adenoma Findings With Long-term Colorectal Cancer Incidence. 2021; 2582(19):2021-2031. Doi: 10.1001/jama.2018.5809

4 Article R. Pólipos colorectais e sua importância clínica Colorectal polyps and their clinical relevance. 2017:50-60

5 Horiuchi A, Tanaka N. Improving quality measures in colonoscopy and its therapeutic intervention. World J Gastroenterol 2014;20 (36):13027-13034. Doi: 10.3748/wjg.v20.i36.13027

6 Hassan C, Antonelli G, Dumonceau JM, et al. Post-polypectomy colonoscopy surveillance: European Society of Gastrointestinal Endoscopy (ESGE) Guideline - Update 2020. Endoscopy 2020;52 (08):687-700. Doi: 10.1055/a-1185-3109

7 Gupta S, Lieberman D, Anderson JC, et al. Recommendations for Follow-Up After Colonoscopy and Polypectomy: A Consensus Update by the US Multi-Society Task Force on Colorectal Cancer. Gastroenterology 2020;158(04):1131-1153.e5. Doi: 10.1053/j. gastro.2019.10.026

8 Jeong YH, Kim KO, Park CS, Kim SB, Lee SH, Jang BI. Risk factors of advanced adenoma in small and diminutive colorectal polyp. J Korean Med Sci 2016;31(09):1426-1430. Doi: 10.3346/ jkms.2016.31.9.1426 
9 Pommergaard HC, Burcharth J, Rosenberg J, Raskov H. The association between location, age and advanced colorectal adenoma characteristics: a propensity-matched analysis. Scand J Gastroenterol 2017;52(01):1-4. Doi: 10.1080/00365521.2016.1218929

10 Maida M, Morreale G, Sinagra E, et al. Quality measures improving endoscopic screening of colorectal cancer: a review of the literature. Expert Rev Anticancer Ther 2019;19(03):223-235. Doi: 10.1080/14737140.2019.1565999

11 Manuscript A, Rate AD. Adenoma Detection Rate and Risk of Colorectal Cancer and Death. 2014;370(14):1298-1306. Doi: 10.1056/NEJMoa1309086.Adenoma

12 Kligman E, Li W, Eckert GJ, Kahi C. Adenoma Detection Rate in Asymptomatic Patients with Positive Fecal Immunochemical Tests. Dig Dis Sci 2018;63(05):1167-1172. Doi: 10.1007| s10620-018-4984-9

13 Ishaq S, Siau K, Harrison E, et al. Technological advances for improving adenoma detection rates: The changing face of colonoscopy. Dig Liver Dis 2017;49(07):721-727. Doi: 10.1016/j. dld.2017.03.030

14 Jiménez-López M, García-Romero CA, Rojas-Illanes MF, MartínezOrdaz JL. Prevalence and risk factors for premalignant lesions in patients younger than 55 years old founded on colonoscopy on a tertiary center. Cir y Cir (English Ed.) 2018;86(03):215-219. Doi: 10.24875/CIRU.M18000034

15 Breau G, Ellis U. Risk Factors Associated With Young-Onset Colorectal Adenomas and Cancer: A Systematic Review and Meta-Analysis of Observational Research. Cancer Contr 2020;27 (01):1073274820976670. Doi: 10.1177/1073274820976670

16 Karsenti D, Tharsis G, Burtin P, et al. Adenoma and advanced neoplasia detection rates increase from 45 years of age. World $\mathrm{J}$ Gastroenterol 2019;25(04):447-456. Doi: 10.3748/wjg.v25.i4.447

17 Kastenberg D, Bertiger G, Brogadir S. Bowel preparation quality scales for colonoscopy. World J Gastroenterol 2018;24(26): 2833-2843. Doi: 10.3748/wjg.v24.i26.2833
18 Kurome M, Kato J, Nawa T, et al. Risk factors for high-grade dysplasia or carcinoma in colorectal adenoma cases treated with endoscopic polypectomy. Eur J Gastroenterol Hepatol 2008;20(02):111-117. Doi: 10.1097/MEG.0b013e3282f1cbef

19 Mannucci A, Zuppardo RA, Rosati R, Di Leo M, Perea J, Cavestro GM. Colorectal cancer screening from 45 years of age: Thesis, antithesis and synthesis. World J Gastroenterol 2019;25(21): 2565-2580. Doi: 10.3748/wjg.v25.i21.2565

20 Bibbins-Domingo K, Grossman DC, Curry SJ, et al; US Preventive Services Task Force. Screening for colorectal cancer: US preventive services task force recommendation statement. JAMA -.JAMA 2016;315(23):2564-2575. Doi: 10.1001/jama.2016.5989

21 VIGITEL - Surveillance of risk and protective factors for chronic diseases by telephone survey. Estimates of frequency and sociodemographic distribution of risk and protective factors for chronic diseases in the capitals of the 26 Brazilian states and the Federal District in 2018. Brasilia; 2019

22 Marguerite JKutyla (PhD)1, 2*, Marcus A. Gray (PhD)1, 3-4*, Courtney von Hippel (PhD)3 LF, Hourigan (PhD)1, 5, Bradley J. Kendall (PhD)1, 5, Amanda Whaley1, Sam O'Connor (MBBS)1, 5 , Gerald J. Holtmann (PhD)1 4-6. Improving the Quality of Bowel Preparation: Rewarding Patients for Success or Intensive Patient Education? Marguerite. 2020 Doi: 10.1159/000510461

23 Chen TH, Hsu CM, Hsu HC, et al. Plasminogen activator inhibitor-1 is associated with the metabolism and development of advanced colonic polyps. Transl Res 2018;200:43-53. Doi: 10.1016/j. trsl.2018.05.010

24 Iwai T, Imai K, Hotta K, et al. Endoscopic prediction of advanced histology in diminutive and small colorectal polyps. J Gastroenterol Hepatol 2019;34(02):397-403. Doi: 10.1111/jgh.14409

25 Vleugels JLA, Hassan C, Senore C, et al. Diminutive Polyps With Advanced Histologic Features Do Not Increase Risk for Metachronous Advanced Colon Neoplasia. Gastroenterology 2019;156(03): 623-634.e3. Doi: 10.1053/j.gastro.2018.10.050 